\title{
OPEN Body mass index and body weight change during adjuvant chemotherapy in colon cancer patients: results from the AVANT trial
}

\author{
Dae-Won Lee ${ }^{1,5}$, Sooyoung $\mathrm{Cho}^{2,5}$, Aesun Shin ${ }^{2,3 凶}$, Sae-Won $\mathrm{Han}^{1,3 \otimes}$ \& Tae-You Kim ${ }^{1,3,4}$
}

While obesity increases colorectal cancer incidence, there are inconsistent results in the prognostic role of obesity or body weight change on survival. This study investigated the prognostic impact of body weight and weight change in stage III or high risk stage II colon cancer patients. We used data from patients enrolled in the phase III AVANT trial. The AVANT trial investigated the efficacy of adding bevacizumab to standard adjuvant chemotherapy (FOFOX or XELOX). Weight change during the first 6 months of adjuvant chemotherapy was measured. Cox proportional hazard model was used to assess the prognostic influence of body weight and weight change. Among 3451 intention-to-treat population, body weight and weight change was measured in $3449(99.9 \%)$ and $2455(71.1 \%)$ patients, respectively. Among 2455 patients, 651 (26.5\%) had weight gain over $5 \mathrm{~kg}$ and 179 (7.3\%) had weight loss over $5 \mathrm{~kg}$. Weight gain was more frequently observed in Asian and male. Neither baseline BMI nor weight change affected recurrence or survival in the Cox proportional hazard model.

Development of colorectal cancer is a heterogeneous process affected by hereditary factor, diet, and gut microbiome $e^{1,2}$. Obesity may increase colorectal cancer incidence through alternating adipocytokine levels and inducing insulin resistance ${ }^{3,4}$. It is suggested that obesity is associated with $30-70 \%$ increase of colorectal cancer incidence in men, although the association between obesity and colorectal cancer incidence is less consistent in women ${ }^{3}$. Approximately $35 \%$ of United States adults are obese and obesity prevalence is increasing in many developing countries that adopt Western lifestyle ${ }^{5,6}$. These findings may partially attribute to the increase of colorectal cancer incidence in developing countries ${ }^{7,8}$

Obesity increases colorectal cancer incidence, but the prognostic role of obesity in patients diagnosed with colorectal cancer remains less conclusive. Although obesity did not impact cancer outcome in several studies ${ }^{9,10}$, most studies revealed negative impact of obesity on cancer survival ${ }^{11-14}$. Obesity may also have negative prognostic role in colorectal cancer patients treated with adjuvant chemotherapy ${ }^{12,13}$. However, the impact of obesity on cancer outcome is inconsistent according to sex. In a study by Meyerhardt et al., which 3759 patients were included, obesity was associated with poor survival in women but not in men ${ }^{11}$. In contrast, negative prognostic role of obesity was shown in men but not in women in the Adjuvant Colon Cancer Endpoints database, which 25,291 colon cancer patients were analyzed ${ }^{12}$.

Body weight change after surgery and during the adjuvant chemotherapy period is frequently observed ${ }^{15}$. However, only few studies have evaluated the association between body weight change and colorectal cancer outcome. Initially, Meyerhardt et al. reported that body weight change did not impact cancer recurrence or death $^{9}$. However, body weight loss was a negative prognostic factor in following studies ${ }^{16,17}$. Using a single center retrospective data, we have previously reported that body weight gain during adjuvant chemotherapy period

\footnotetext{
${ }^{1}$ Department of Internal Medicine, Seoul National University Hospital, 101 Daehang-Ro, Jongno-Gu, Seoul 03080, Republic of Korea. ${ }^{2}$ Department of Preventive Medicine, Seoul National University College of Medicine, 103 Daehang-Ro, Jongno-Gu, Seoul 03080, Republic of Korea. ${ }^{3}$ Cancer Research Institute, Seoul National University College of Medicine, Seoul, Republic of Korea. ${ }^{4}$ Department of Molecular Medicine and Biopharmaceutical Sciences, Graduate School of Convergence Science and Technology, Seoul National University, Seoul, Republic of Korea. ${ }^{5}$ These authors contributed equally: Dae-Won Lee and Sooyoung Cho. ${ }^{\varpi}$ email: shinaesun@snu.ac.kr; saewon1@snu.ac.kr
} 
may have detrimental effect in overweight or obese patients ${ }^{10}$. This study was planned to validate our previous finding in a prospective clinical trial.

To date, the prognostic role of body weight and body weight change during adjuvant chemotherapy period remains inconclusive. We examined the prognostic role of body weight and weight change in patients who participated in a phase III AVANT trial. AVANT trial investigated adding bevacizumab with either 5-fluorouracil/ leucovorin/oxaliplatin (FOLFOX) or capecitabine/oxaliplatin (XELOX) in curatively resected stage III or highrisk stage II colon cancer patients ${ }^{18}$.

\section{Methods}

Study population. Patients enrolled in the AVANT trial was included (ClinicalTrial.gov Identifier: NCT00112918) ${ }^{18}$. Study designs, key inclusion criteria, and exclusion criteria have previously been described in detail ${ }^{18}$. Histologically confirmed stage III or high-risk stage II colon cancer were included. The AVANT trial was a 3-arm study comparing FOLFOX4-bevacizumab versus FOLFOX4 or XELOX-bevacizumab versus FOLFOX4. Patients were 1:1:1 randomly assigned to receive either FOLFOX 4, FOLFOX4-bevacizumab, or XELOX-bevacizumab. From Dec 2004 to June 2007, 3,451 patients were randomized on the treatment arm (1151 received FOLFOX 4, 1155 received bevacizumab-FOLFOX4, and 1145 received bevacizumab-XELOX). Protocol was approved by institutional review boards or ethics review committees at each participating sites and was conducted in accordance with the declaration of Helsinki (3451 patients from 330 centers in 34 countries worldwide were randomly assigned). In our institute, the study protocol was reviewed and approved by the institutional review board of Seoul National University Hospital, Seoul, Korea [H-0412-139-011]. Written informed consent was provided by all participants before study enrollment. Access to the database by authors were approved by the sponsor Roche from "ClinicalStudyDataRequest.com".

Body mass index (BMI) and body weight change. Body mass index (BMI) was calculated by person's weight in kilograms ( $\mathrm{kg}$ ) divided by the height in meters squared $\left(\mathrm{kg} / \mathrm{m}^{2}\right)$. Body weight measured on study enrollment was defined as baseline body weight. We categorized BMI as underweight (less than $18.5 \mathrm{~kg} /$ $\mathrm{m}^{2}$ ), normal $\left(18.5-24.9 \mathrm{~kg} / \mathrm{m}^{2}\right)$, overweight $\left(25.0-29.9 \mathrm{~kg} / \mathrm{m}^{2}\right)$, and obese $\left(\geq 30 \mathrm{~kg} / \mathrm{m}^{2}\right)$. Body weight measured 6 months after chemotherapy initiation was used as post-treatment weight. Body weight change during adjuvant chemotherapy period was measured by comparing post-adjuvant chemotherapy weight with baseline weight.

Study end points. The primary objective was to investigate the impact of BMI and body weight change on disease-free survival (DFS). DFS was calculated from the date of randomization to recurrence, new occurrence of colorectal cancer, or death from any cause. Data from patients who were free of events were censored at the last date at which they were known to be disease-free. Secondary objective was to investigate the impact of BMI and body weight change on overall survival (OS). OS was calculated from the time of randomization to death from any cause. Patients who were free of events were censored at the known date of confirmed alive. Tumor assessment was pre-scheduled every 6 months after randomization until year 4 , then annually thereafter.

Statistical analysis. We compared baseline characteristics including age at entry, sex, disease stage, ECOG performance scale, chemotherapy regimen, ethnic origin, and smoking history by BMI groups using Chi square test and Fisher's exact test. Cox proportional hazard model was used to estimate hazard ratios (HRs) and its corresponding 95\% confidence intervals (CIs) of BMI and weight change for DFS and OS. We identified the best fitting model using likelihood ratio test and Akaike's information criterion ${ }^{19,20}$. Disease stage, ECOG performance scale and chemotherapy regimen were selected in the final model. Tests of significance were two-sided, with alpha level of 0.05 . Statistical analyses were performed using R version 3.4 (R Foundation for Statistical Computing, Vienna, Austria).

\section{Results}

Baseline characteristics and survival outcome according to baseline BMI. Of the total of 3451 intention-to-treat population, baseline BMI was measured in 3449 patients. Patient characteristics according to baseline BMI are described in Table 1. According to the WHO definition, 93 patients (2.7\%) were underweight $\left(\mathrm{BMI}<18.5 \mathrm{~kg} / \mathrm{m}^{2}\right), 1643(47.6 \%)$ had normal weight $\left(18.5-24.9 \mathrm{~kg} / \mathrm{m}^{2}\right), 1239(35.9 \%)$ had overweight $\left(25-29.9 \mathrm{~kg} / \mathrm{m}^{2}\right)$, and $474(13.7 \%)$ were obese $\left(\geq 30 \mathrm{~kg} / \mathrm{m}^{2}\right)$. Underweight and normal weight patients were more likely to be younger and had higher proportion of female, never smoker, and Asian population compared to overweight and obese patients. ECOG performance scale, chemotherapy regimen, and disease stage was similar regardless of BMI groups (Table 1 ).

Among 3449 patients, 854 (24.8\%) patients experienced cancer recurrence, and 459 (13.3\%) patients died. The relation between baseline characteristics and DFS is shown in Table 2. The mean follow-up period was 37.8 months. Older age, stage III disease, and poor ECOG performance status was associated with worse DFS. However, baseline BMI status did not affect DFS (Table 2) or OS (Supplementary Table 1). Subgroup analysis according to ethnic was done and baseline BMI did not affect DFS nor OS in each ethnic group.

Body weight change and colon cancer outcome. Body weight change during the first 6 months of adjuvant chemotherapy was measured. Among 3449 patients with baseline BMI, 2455 (71.1\%) patients had data of body weight measured 6 months after the initiation of adjuvant chemotherapy. To identify the effect of body weight change during chemotherapy treatment, 2284 patients who received at least $50 \%$ of scheduled chemotherapy was included in the analysis of body weight change. Three different parameters were analyzed; absolute 


\begin{tabular}{|c|c|c|c|c|c|c|}
\hline & \multirow[b]{2}{*}{ Total } & \multicolumn{4}{|c|}{ Body Mass Index $\left(\mathrm{kg} / \mathrm{m}^{2}\right)$} & \\
\hline & & $\begin{array}{l}\text { Underweight } \\
<18.5\end{array}$ & \begin{tabular}{|l|} 
Normal \\
$18.5-24.9$
\end{tabular} & $\begin{array}{l}\text { Overweight } \\
25-29.9\end{array}$ & $\begin{array}{l}\text { Obese } \\
\geq 30\end{array}$ & \\
\hline Total & 3449 & $93(2.7 \%)$ & $1643(47.6 \%)$ & $1239(35.9 \%)$ & $474(13.7 \%)$ & \\
\hline Age & & & & & & $<0.001$ \\
\hline$<65$ years & $2456(71.2 \%)$ & $79(84.9 \%)$ & $1231(74.9 \%)$ & $816(65.9 \%)$ & $330(69.6 \%)$ & \\
\hline$\geq 65$ years & $993(28.8 \%)$ & $14(15.1 \%)$ & $412(25.1 \%)$ & $423(34.1 \%)$ & $144(30.4 \%)$ & \\
\hline Sex & & & & & & $<0.001$ \\
\hline Male & $1868(54.2 \%)$ & $25(26.9 \%)$ & $803(48.9 \%)$ & $768(62.0 \%)$ & $272(57.4 \%)$ & \\
\hline Female & $1581(45.8 \%)$ & $68(73.1 \%)$ & $840(51.1 \%)$ & $471(38.0 \%)$ & $202(42.6 \%)$ & \\
\hline Disease stage & & & & & & 0.35 \\
\hline Stage II (high-risk) & $577(16.7 \%)$ & $23(24.7 \%)$ & $286(17.4 \%)$ & $195(15.7 \%)$ & $73(15.4 \%)$ & \\
\hline Stage III, N1 & $1750(50.7 \%)$ & $42(45.2 \%)$ & $819(49.8 \%)$ & $641(51.7 \%)$ & $248(52.3 \%)$ & \\
\hline Stage III, N2 & $1122(32.5 \%)$ & $28(30.1 \%)$ & $538(32.7 \%)$ & $403(32.5 \%)$ & $153(32.3 \%)$ & \\
\hline ECOG performance scale & & & & & & 0.35 \\
\hline 0 & $2959(85.8 \%)$ & $76(81.7 \%)$ & $1418(86.3 \%)$ & $1068(86.2 \%)$ & $397(83.8 \%)$ & \\
\hline 1 & $487(14.1 \%)$ & $17(18.3 \%)$ & $224(13.6 \%)$ & $170(13.7 \%)$ & $76(16.0 \%)$ & \\
\hline (Missing) & $3(0.1 \%)$ & $0(0.0 \%)$ & $1(0.1 \%)$ & $1(0.1 \%)$ & $1(0.2 \%)$ & \\
\hline Chemotherapy regimen & & & & & & 0.78 \\
\hline FOLFOX4 & $1150(33.3 \%)$ & $30(32.3 \%)$ & $554(33.7 \%)$ & $417(33.7 \%)$ & $149(31.4 \%)$ & \\
\hline Bevacizumab-FOLFOX4 & $1154(33.5 \%)$ & $27(29.0 \%)$ & $548(33.4 \%)$ & $408(32.9 \%)$ & $171(36.1 \%)$ & \\
\hline Bevacizumab-XELOX & $1145(33.2 \%))$ & $36(38.7 \%)$ & $541(32.9 \%)$ & $414(33.4 \%)$ & $154(32.5 \%)$ & \\
\hline Ethnic origin & & & & & & $<0.001^{\star}$ \\
\hline Asian & $434(12.6 \%)$ & $25(26.9 \%)$ & $319(19.4 \%)$ & $82(6.6 \%)$ & $8(1.7 \%)$ & \\
\hline White & $2893(83.9 \%)$ & $61(65.6 \%)$ & $1279(77.8 \%)$ & $1105(89.2 \%)$ & $448(94.5 \%)$ & \\
\hline Other & $122(3.5 \%)$ & $7(7.5 \%)$ & $45(2.7 \%)$ & $52(4.2 \%)$ & $18(3.8 \%)$ & \\
\hline Smoking history & & & & & & $<0.001$ \\
\hline Never smoked & $1471(42.7 \%)$ & $43(46.2 \%)$ & $714(43.5 \%)$ & $522(42.1 \%)$ & $192(40.5 \%)$ & \\
\hline Past smoker & $778(22.6 \%)$ & $18(19.4 \%)$ & $329(20.0 \%)$ & $299(24.1 \%)$ & $132(27.8 \%)$ & \\
\hline Current smoker & $241(7.0 \%)$ & $9(9.7 \%)$ & $141(8.6 \%)$ & $66(5.3 \%)$ & $25(5.3 \%)$ & \\
\hline Data missing & $959(27.8 \%)$ & $23(24.7 \%)$ & $459(27.9 \%)$ & $352(28.4 \%)$ & $125(26.4 \%)$ & \\
\hline
\end{tabular}

Table 1. Baseline characteristics according to baseline BMI. ${ }^{\star}$ Fisher’s exact test.

body weight change ( $\leq-10 \mathrm{~kg},-9.9$ to $-5 \mathrm{~kg},-4.9$ to $4.9 \mathrm{~kg}, 5$ to $9.9 \mathrm{~kg}, \geq 10 \mathrm{~kg}$ ), relative body weight change ( $\leq-10 \%,-9.9$ to $-5 \%,-4.9$ to $4.9 \%, 5$ to $9.9 \%, \geq 10 \%)$, and BMI change ( $\leq-2 \mathrm{~kg} / \mathrm{m}^{2},-1.9$ to $1.9 \mathrm{~kg} / \mathrm{m}^{2}, \geq 2 \mathrm{~kg} /$ $\mathrm{m}^{2}$ ). Detailed body weight change according to each parameter are shown in Table 3. Body weight change was frequent during the course of adjuvant chemotherapy. Among 2455 patients, 179 (7.3\%) had weight loss over $5 \mathrm{~kg}$ and $651(26.5 \%)$ had weight gain over $5 \mathrm{~kg}$. The pattern of body weight change was different according to patient's ethnicity and sex. Asian patients had higher proportion of weight gain over $5 \mathrm{~kg}(26.6 \% \mathrm{vs} .22 .9 \%)$ and lower proportion of weight loss over $5 \mathrm{~kg}$ (1.8\% vs. 6.7\%) compared to White. In addition, weight gain over $5 \mathrm{~kg}$ was more frequent in male compared to women $(27.2 \%$ vs. $20.3 \%, p=0.004)$. We next evaluated the prognostic value of body weight change. Body weight change in all three parameter was not associated with DFS or OS (Table 3, Supplementary Table 2). Body weight change still did not impact DFS after adjusting for disease stage, ECOG performance status, and chemotherapy regimen. Subgroup analysis was performed to identify the impact of body weight change according to baseline BMI status, sex, and ethnic origin. However, there was no correlation between body weight change and DFS or OS in any subgroups. Detailed data of body weight change and DFS according to sex and age are shown in Supplementary Tables 3 and 4, respectively.

\section{Discussion}

Although obesity increases colon cancer incidence, prognostic role of obesity and body weight change remains inconclusive. This study investigated the prognostic effect of baseline BMI and body weight change in stage III and high-risk II colon cancer patients using the data of the AVANT trial. We selected AVANT trial to prove the hypothesis as patients included in this study received either FOLFOX or XELOX which is the standard treatment of choice in stage III colon cancer after complete resection of the tumor ${ }^{21,22}$. This study results shows baseline $\mathrm{BMI}$ or body weight change does not impact colon cancer recurrence or survival.

Many studies investigated the prognostic role of obesity in patients diagnosed with colorectal cancer ${ }^{9-14}$. Meyerhardt et al. reported that obesity $\left(B M I \geq 30 \mathrm{~kg} / \mathrm{m}^{2}\right.$ ) was associated with poor survival in women (hazard ratio [HR] of 1.34 for mortality) but not in men in 3759 high-risk stage II and stage III colon cancer patients ${ }^{11}$. However, the negative impact of obesity in women was not shown in the ACCENT database which included 25,291 colon cancer patients ${ }^{12}$. In the multivariate analysis, obesity was associated with poor survival in men but 


\begin{tabular}{|c|c|c|c|c|}
\hline & Total & $\Sigma \mathrm{F} / \mathrm{U}$ months & DFS event & Crude HR \\
\hline \multicolumn{5}{|l|}{ Age } \\
\hline$<65$ years & 2,456 & $93,666.6$ & 580 & Ref \\
\hline$\geq 65$ years & 993 & $36,896.7$ & 274 & $1.20(1.04-1.39)$ \\
\hline \multicolumn{5}{|l|}{ Sex } \\
\hline Male & 1868 & $70,752.6$ & 479 & Ref \\
\hline Female & 1581 & $59,810.7$ & 375 & $0.93(0.82-1.07)$ \\
\hline \multicolumn{5}{|l|}{ Disease stage } \\
\hline Stage II (high-risk) & 577 & $24,622.8$ & 83 & Ref \\
\hline Stage III N1 & 1750 & $67,418.8$ & 367 & $1.55(1.22-1.97)$ \\
\hline Stage III N2 & 1122 & $38,521.7$ & 404 & $2.99(2.36-3.79)$ \\
\hline \multicolumn{5}{|l|}{ ECOG performance scale } \\
\hline 0 & 2959 & $113,016.6$ & 695 & Ref \\
\hline 1 & 487 & $17,398.3$ & 159 & $1.48(1.25-1.76)$ \\
\hline (Missing) & 3 & & & \\
\hline \multicolumn{5}{|l|}{ Chemotherapy regimen } \\
\hline FOLFOX4 & 1150 & $43,882.0$ & 263 & Ref \\
\hline FOLFOX4 + Bevacizumab & 1154 & $43,790.2$ & 309 & $1.17(0.99-1.38)$ \\
\hline XELOX + Bevacizumab & 1145 & $42,891.1$ & 282 & $1.09(0.92-1.29)$ \\
\hline \multicolumn{5}{|l|}{ Ethnic origin } \\
\hline White & 2893 & $110,598.1$ & 731 & Ref \\
\hline Asian & 434 & $15,815.8$ & 94 & $0.87(0.70-1.08)$ \\
\hline Other & 122 & 4149.3 & 29 & $1.04(0.72-1.51)$ \\
\hline \multicolumn{5}{|l|}{ Smoking history at baseline } \\
\hline Never smoked & 1471 & $52,766.8$ & 359 & Ref \\
\hline Past smoker & 778 & $28,253.3$ & 181 & $0.94(0.79-1.12)$ \\
\hline Current smoker & 241 & 8486.6 & 60 & $1.05(0.80-1.37)$ \\
\hline Data missing & 959 & & & \\
\hline \multicolumn{5}{|l|}{ Baseline BMI (kg/m²) } \\
\hline$<18.5$ : underweight & 93 & 3608.9 & 19 & $0.78(0.49-1.23)$ \\
\hline 18.5-24.9: normal & 1643 & $61,241.4$ & 419 & Ref \\
\hline 25.0-29.9: overweight & 1239 & $47,656.4$ & 309 & $0.96(0.83-1.11)$ \\
\hline 30.0-34.9: moderately obese & 381 & $14,722.2$ & 86 & $0.85(0.68-1.08)$ \\
\hline$\geq 35:$ severely obese & 93 & 3334.4 & 21 & $0.93(0.60-1.44)$ \\
\hline
\end{tabular}

Table 2. Univariate analysis for disease-free survival.

\begin{tabular}{|c|c|c|c|c|c|}
\hline & Total $(N=2455)$ & $\Sigma F / U$ months & DFS event & Crude HR & Adjusted HR \\
\hline \multicolumn{6}{|c|}{ Weight change (kg) } \\
\hline$\leq-10$ & $31(1.3 \%)$ & 1195.2 & 10 & $1.43(0.76-2.67)$ & $1.19(0.63-2.23)$ \\
\hline-9.9 to -5 & $148(6.0 \%)$ & 6218.9 & 30 & $0.81(0.56-1.18)$ & $0.81(0.56-1.17)$ \\
\hline-4.9 to 4.9 & $1625(67.4 \%)$ & $65,781.4$ & 390 & Ref & Ref \\
\hline 5 to 9.9 & $520(21.2 \%)$ & $21,139.1$ & 128 & $1.03(0.84-1.26)$ & $1.07(0.88-1.31)$ \\
\hline$\geq 10$ & $131(5.3 \%)$ & 5485.2 & 27 & $0.84(0.57-1.24)$ & $0.85(0.58-1.26)$ \\
\hline \multicolumn{6}{|c|}{ Weight change (\%) } \\
\hline$\leq-10$ & $77(3.1 \%)$ & 3062.3 & 21 & $1.16(0.74-1.80)$ & $1.06(0.68-1.65)$ \\
\hline-9.9 to -5 & $175(7.1 \%)$ & 7303.6 & 39 & $0.91(0.65-1.27)$ & $0.92(0.66-1.28)$ \\
\hline-4.9 to 4.9 & $1320(53.8 \%)$ & $53,287.7$ & 316 & Ref & Ref \\
\hline 5 to 9.9 & $543(22.1 \%)$ & $22,125.8$ & 131 & $1.01(0.82-1.24)$ & $1.03(0.84-1.26)$ \\
\hline$\geq 10$ & $340(13.8 \%)$ & $14,040.5$ & 78 & $0.94(0.74-1.21)$ & $0.97(0.76-1.25)$ \\
\hline \multicolumn{6}{|c|}{ Change in body mass index $\left(\mathrm{kg}\right.$ per $\left.\mathrm{m}^{2}\right)$} \\
\hline$\leq-2$ & $139(5.7 \%)$ & 5678.1 & 34 & $1.02(0.72-1.44)$ & $0.97(0.68-1.37)$ \\
\hline-1.9 to 1.9 & $1801(73.3 \%)$ & $73,019.0$ & 431 & Ref & Ref \\
\hline$\geq 2$ & $515(21.0 \%)$ & $21,122.6$ & 120 & $0.97(0.79-1.19)$ & $1.00(0.82-1.23)$ \\
\hline
\end{tabular}

Table 3. Body weight change and disease-free survival. Adjusted for disease stage, ECOG performance scale, chemotherapy regimen. 
not in women ${ }^{12}$. Other studies showed negative impact of obesity on survival but sex difference was not shown or data on sex was not provided ${ }^{13,14}$. Evidences show that the risk of obesity on colorectal cancer development may be sex specific ${ }^{3}$. There is a hypothesis that insulin and insulin-like growth factor axis in colorectal neoplasia is different between sex, and this may partially explain the different role of obesity among $\operatorname{sex}^{23}$. Moreover, the risk of obesity on colorectal cancer risk is different among menopausal status ${ }^{24}$. Obesity was associated with colorectal cancer risk in premenopausal but not in postmenopausal women. Sex and hormone status may have contributed to the conflicting results of previous studies. However, in the present study, baseline BMI did not affect recurrence or survival in any subgroup of patients. Obesity was not associated with cancer outcome regardless of sex and age. We believe future larger cohort studies are needed to confirm these findings.

Life style modification and weight change are very common in patients diagnosed with cancer ${ }^{25}$. Physical activity reduces the risk of cancer recurrence and overall mortality in colorectal cancer patients ${ }^{26}$. In the present study, body weight gain was more frequent during adjuvant chemotherapy period compared to body weight loss. Twenty-five percent of patients had weight gain over $5 \mathrm{~kg}$ during adjuvant chemotherapy and 7.3 percent had weight loss over $5 \mathrm{~kg}$. Weight gain was more frequently observed in Asian and male population, respectively. While body weight change during adjuvant chemotherapy period is frequently observed, only few studies have investigated the prognostic role of body weight change on colorectal cancer outcome. Neither weight gain nor loss was associated with cancer recurrence or death in 1053 stage III colon cancer patients treated with adjuvant

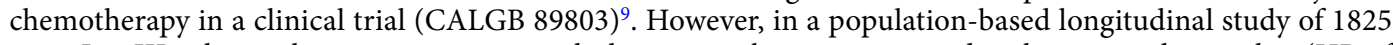
stage I to III colorectal cancer patients, weight loss over $5 \mathrm{~kg}$ was associated with increased mortality (HR of 1.63) while weight gain did not impact cancer outcome $e^{27}$. The negative prognostic impact of weight loss after diagnosis was also shown in 2781 stage I-III colorectal cancer patients from Kaiser Permanente Northern California population ${ }^{17}$. Loss of $10 \%$ or more body weight was associated with increase in colorectal cancer-specific mortality (HR of 3.20) ${ }^{17}$. In breast cancer patients, although controversial, many studies showed possible negative prognostic role of body weight gain after cancer diagnosis ${ }^{28,29}$. However, in colorectal cancer, only 1 study showed negative prognostic role of body gain after diagnosis. In a single institution retrospective study, body weight gain ( $5 \mathrm{~kg}$ or more) in overweight or obese patients was associated with poor outcome ${ }^{10}$. Among 522 stage III or high-risk stage II colorectal cancer patients treated with adjuvant FOLFOX in South Korea, body weight gain ( $\geq 5 \mathrm{~kg}$ ) during adjuvant chemotherapy was associated with inferior disease-free survival (DFS) (HR of 2.04 ) in overweight and obese patients ${ }^{10}$. In the present study, body weight gain or loss was not associated with recurrence or survival. Weight change still did not impact cancer outcomes when stratified by ethnic, sex, age, or baseline BMI. Weight change during adjuvant chemotherapy may not affect recurrence or survival in colon cancer treated with curative surgery followed by adjuvant FOLFOX/XELOX chemotherapy.

The limitation of the present study is that we could not assess other measures associated with metabolic dysregulation including waist circumference, waist-hip ratio, physical activity, and metabolic syndrome. The purpose of this study was not pre-defined in the clinical trial, so these measures were not collected. As body fat composition and distribution is affected by sex, age, and ethnics, using BMI may have pitfalls in assessing the true extent of obesity ${ }^{30}$. These limitations may have affected inconsistent results of baseline BMI and body weight change on prognosis of cancer patients. Nevertheless, BMI is a simple measure of obesity which is readily available and commonly used. Future comprehensive analysis of obesity is needed to evaluate the association between metabolic dysregulation and cancer outcome. In addition, evaluating adipocytokines level such as leptin, resistin, and adiponectin will help physicians to understand metabolic status of a patient. Another limitation of this study is that the time between body weight measurements is relatively short (6 months). Long-term body weight change might have different effect on prognostic outcome and future study is warranted.

\section{Conclusion}

This study shows that neither BMI nor weight change were associated with cancer recurrence or survival in patients enrolled in the AVANT trial.

\section{Data availability}

Any requested data and materials will be considered by the corresponding author.

Received: 25 April 2020; Accepted: 27 October 2020

Published online: 10 November 2020

\section{References}

1. Grady, W. M. \& Carethers, J. M. Genomic and epigenetic instability in colorectal cancer pathogenesis. Gastroenterology 135, 1079-1099 (2008).

2. Schwabe, R. F. \& Jobin, C. The microbiome and cancer. Nat. Rev. Cancer 13, 800-812. https://doi.org/10.1038/nrc3610 (2013).

3. Bardou, M., Barkun, A. N. \& Martel, M. Obesity and colorectal cancer. Gut 62, 933-947 (2013).

4. Pollak, M. Insulin and insulin-like growth factor signalling in neoplasia. Nat. Rev. Cancer 8, 915-928. https://doi.org/10.1038/ nrc2536 (2008).

5. Flegal, K. M., Carroll, M. D., Kit, B. K. \& Ogden, C. L. Prevalence of obesity and trends in the distribution of body mass index among US adults, 1999-2010. JAMA 307, 491-497 (2012).

6. Popkin, B. M. \& Slining, M. M. New dynamics in global obesity facing low- and middle-income countries. Obes. Rev. 14(Suppl 2), 11-20. https://doi.org/10.1111/obr.12102 (2013).

7. Center, M. M., Jemal, A., Smith, R. A. \& Ward, E. Worldwide variations in colorectal cancer. CA Cancer J. Clin. 59, 366-378. https ://doi.org/10.3322/caac.20038 (2009).

8. Jung, K.-W. et al. Cancer statistics in Korea: Incidence, mortality, survival, and prevalence in 2014. Cancer Res. Treat. 49, 292 (2017). 
9. Meyerhardt, J. A. et al. Impact of body mass index and weight change after treatment on cancer recurrence and survival in patients with stage III colon cancer: Findings from Cancer and Leukemia Group B 89803. J. Clin. Oncol. 26, 4109-4115. https://doi. org/10.1200/JCO.2007.15.6687 (2008).

10. Lee, D. W. et al. Prognostic influence of body mass index and body weight gain during adjuvant FOLFOX chemotherapy in Korean colorectal cancer patients. BMC Cancer 15, 690. https://doi.org/10.1186/s12885-015-1704-0 (2015).

11. Meyerhardt, J. A. et al. Influence of body mass index on outcomes and treatment-related toxicity in patients with colon carcinoma. Cancer 98, 484-495. https://doi.org/10.1002/cncr.11544 (2003).

12. Sinicrope, F. A. et al. Body mass index at diagnosis and survival among colon cancer patients enrolled in clinical trials of adjuvant chemotherapy. Cancer 119, 1528-1536. https://doi.org/10.1002/cncr.27938 (2013).

13. Dignam, J. J. et al. Body mass index and outcomes in patients who receive adjuvant chemotherapy for colon cancer. J. Natl. Cancer Inst. 98, 1647-1654 (2006).

14. Sinicrope, F. A., Foster, N. R., Sargent, D. J., O'Connell, M. J. \& Rankin, C. Obesity is an independent prognostic variable in colon cancer survivors. Clin. Cancer Res. 16, 1884-1893. https://doi.org/10.1158/1078-0432.CCR-09-2636 (2010).

15. Winkels, R. M. et al. Changes in body weight in patients with colorectal cancer treated with surgery and adjuvant chemotherapy: An observational study. Cancer Treat. Res. Commun. 9, 111-115. https://doi.org/10.1016/j.ctarc.2016.09.002 (2016).

16. Alberts, S. R. et al. Effect of oxaliplatin, fluorouracil, and leucovorin with or without cetuximab on survival among patients with resected stage III colon cancer: A randomized trial. JAMA 307, 1383-1393. https://doi.org/10.1001/jama.2012.385 (2012).

17. Meyerhardt, J. A. et al. Association of weight change after colorectal cancer diagnosis and outcomes in the kaiser permanente northern california population. Cancer Epidemiol. Biomark. Prev. 26, 30-37. https://doi.org/10.1158/1055-9965.EPI-16-0145 (2017).

18. de Gramont, A. et al. Bevacizumab plus oxaliplatin-based chemotherapy as adjuvant treatment for colon cancer (AVANT): A phase 3 randomised controlled trial. Lancet Oncol. 13, 1225-1233 (2012).

19. Buse, A. The likelihood ratio, Wald, and Lagrange multiplier tests: An expository note. Am. Stat. 36, 153-157 (1982).

20. Sakamoto, Y., Ishiguro, M. \& Kitagawa, G. Akaike Information Criterion Statistics (Springer, Netherlands, 1986).

21. Andre, T. et al. Improved overall survival with oxaliplatin, fluorouracil, and leucovorin as adjuvant treatment in stage II or III colon cancer in the MOSAIC trial. J. Clin. Oncol. 27, 3109-3116. https://doi.org/10.1200/JCO.2008.20.6771 (2009).

22. Haller, D. G. et al. Capecitabine plus oxaliplatin compared with fluorouracil and folinic acid as adjuvant therapy for stage III colon cancer. J. Clin. Oncol. 29, 1465-1471. https://doi.org/10.1200/JCO.2010.33.6297 (2011).

23. Yamaji, T., Iwasaki, M., Sasazuki, S. \& Tsugane, S. Gender difference in the association of insulin and the insulin-like growth factor axis with colorectal neoplasia. Int. J. Obes. (Lond.) 36, 440-447. https://doi.org/10.1038/ijo.2011.114 (2012).

24. Reeves, G. K. et al. Cancer incidence and mortality in relation to body mass index in the Million Women Study: Cohort study. BMJ 335, 1134. https://doi.org/10.1136/bmj.39367.495995.AE (2007).

25. Patterson, R. E. et al. Changes in diet, physical activity, and supplement use among adults diagnosed with cancer. J. Am. Diet. Assoc. 103, 323-328. https://doi.org/10.1053/jada.2003.50045 (2003).

26. Meyerhardt, J. A. et al. Impact of physical activity on cancer recurrence and survival in patients with stage III colon cancer: Findings from CALGB 89803. J. Clin. Oncol. 24, 3535-3541. https://doi.org/10.1200/JCO.2006.06.0863 (2006).

27. Baade, P. D. et al. The impact of body mass index and physical activity on mortality among patients with colorectal cancer in Queensland, Australia. Cancer Epidemiol. Biomark. Prev. 20, 1410-1420. https://doi.org/10.1158/1055-9965.EPI-11-0079 (2011).

28. Kroenke, C. H., Chen, W. Y., Rosner, B. \& Holmes, M. D. Weight, weight gain, and survival after breast cancer diagnosis. J. Clin. Oncol. 23, 1370-1378. https://doi.org/10.1200/JCO.2005.01.079 (2005).

29. Chen, X. et al. Obesity and weight change in relation to breast cancer survival. Breast Cancer Res. Treat. 122, 823-833. https://doi. org/10.1007/s10549-009-0708-3 (2010).

30. Burkhauser, R. V. \& Cawley, J. Beyond BMI: The value of more accurate measures of fatness and obesity in social science research. J. Health Econ. 27, 519-529. https://doi.org/10.1016/j.jhealeco.2007.05.005 (2008).

\section{Author contributions}

D.W.L., A.S. and S.W.H. were involved in study concept and design. D.W.L., S.C. and A.S. involved in data acquisition. Analysis and interpretation of data was done by D.W.L., S.C. and A.S. Manuscript was written by D.W.L. and S.W.H. Manuscript review and final approval was done by D.W.L., S.C., A.S., S.W.H., and T.Y.K.

\section{Funding}

There was no funding for the present study.

\section{Competing interests}

The authors declare no competing interests.

\section{Additional information}

Supplementary information is available for this paper at https://doi.org/10.1038/s41598-020-76643-9.

Correspondence and requests for materials should be addressed to A.S. or S.-W.H.

Reprints and permissions information is available at www.nature.com/reprints.

Publisher's note Springer Nature remains neutral with regard to jurisdictional claims in published maps and institutional affiliations.

(c) (i) Open Access This article is licensed under a Creative Commons Attribution 4.0 International cc) License, which permits use, sharing, adaptation, distribution and reproduction in any medium or format, as long as you give appropriate credit to the original author(s) and the source, provide a link to the Creative Commons licence, and indicate if changes were made. The images or other third party material in this article are included in the article's Creative Commons licence, unless indicated otherwise in a credit line to the material. If material is not included in the article's Creative Commons licence and your intended use is not permitted by statutory regulation or exceeds the permitted use, you will need to obtain permission directly from the copyright holder. To view a copy of this licence, visit http://creativecommons.org/licenses/by/4.0/.

(C) The Author(s) 2020 